\title{
Factors Associated with the Survival Outcome of Hepatocellular Carcinoma Patients on Supportive Care in a Tertiary Hospital in South-West Nigeria
}

\author{
Dr. Olusegun Adekanle, \\ Dr. Oluwasegun Ijarotimi,
}

Consultant Physician, Gastro-intestinal Unit, Department of Medicine,

Faculty of Clinical sciences, Obafemi Awolowo University Ile-Ife,

Osun State, Nigeria

Dr. Akinwumu Oluwole Komolafe,

Consultant Histopathologist, Department of Morbid Anatomy, Faculty of

Basic Medical Sciences, Obafemi Awolowo University Ile-Ife,

Osun State, Nigeria

Dr. Samuel Anu Olowookere,

Consultant Family Physician, Department of Community Health, Faculty of Clinical sciences, Obafemi Awolowo University Ile-Ife, Osun State, Nigeria

\section{Dr. Comfort Olusola Famurewa,}

Consultant Radiologist, Department of Radiology, Faculty of Clinical

Sciences, Obafemi Awolowo University Ile-Ife, Osun State, Nigeria

\section{Prof. Dennis A. Ndububa,}

Consultant Physician, Gastro-intestinal Unit, Department of Medicine,

Faculty of Clinical sciences, Obafemi Awolowo University Ile-Ife,

Osun State, Nigeria

Doi:10.19044/esj.2019.v15n24p59 ～URL:http://dx.doi.org/10.19044/esj.2019.v15n24p59

Abstract

Background: Hepatocellular carcinoma (HCC) is a primary liver cancer. This study assessed the factors associated with the survival outcome of HCC on supportive care. Methods: This was a prospective cohort study carried out from January 2010 to June 2016 on cases of HCC recruited into a cancer data registry. Clinical, laboratory and survival outcomes were obtained. Data obtained were analyzed using descriptive and inferential statistics. Results: A total of 149 cases were analyzed: 120 (80.5\%) males and 29 (19.5\%) females. Age range was 18-87years, with mean (SD) being 45.0 (14.3) years. Identifiable aetiological factors were hepatitis B and C viruses, alcohol and herbal preparations in $94 \%$ while no risk factor was identified in $6 \%$. Some risks co-occurred in multiples in $71.2 \%$ of cases. The overall 
median survival was 20 days, and general survival was $59.1 \%$ at two weeks, $33.6 \%$ at one month, and only $7.3 \%$ surviving beyond thirty one days to two years. The survival of cases, according to the Child-Pugh (CTP) class, was CTP A: 36 days (ranged 4 to 730 days), CTP class B: 22 days (ranged 1 to 210 days) and CTP class C: 14 days (ranged 2 to 660 days). Higher proportion of young cases was HBsAg positive. Factors significantly associated with survival outcome included older age, female sex, abdominal pain, jaundice, elevated creatinine, bilirubin, AST, ALT, white cell count and hyponatreamia. Conclusion: Overall survival outcome among cases of $\mathrm{HCC}$ was poor. It is necessary to prevent $\mathrm{HBV}$, reduce alcohol use, detect and treat $\mathrm{HCC}$ early.

Key words: Factors, survival outcome, Hepatocellular carcinoma

\section{Introduction}

Hepatocellular carcinoma (HCC) is a primary malignancy of hepatocytes and it is a common liver cancer with dismal prognosis (Okonkwo et al. 2011). HCC usually presents with a right upper abdominal mass, pain and weight loss. The disease is rapidly fatal within a period of six months and some patients die during hospital admission from complications of the disease (Ndububa et al. 2010 and Yang et al. 2017). Treatment modalities in advanced countries of the world show some rewarding results as the five year survival period following a liver resection for HCC could be up to $26 \%$ (Neeff et al. 2009). Liver transplantation, on the other hand, has been reported in one study to have a ten years post-surgery survival rate of $51.3 \%$ (Tinoco-Gonzalez et al. 2016). At the late stages, median survival periods of 9 months and 6.8 months respectively were reported among untreated cases from two studies (Cabibbo et al. 2012 and Giannini et al. 2015).

There are reports that clinical parameters as well as electrolyte and liver function abnormalities affect the survival of HCC. A study reported that female gender, ascites and a multi-nodular liver masses were independent predictors of survival among untreated cases of HCC (Cabibbo et al. 2012). Another study reported a low serum albumin, elevation of both bilirubin and international normalized ratio (INR) as being significantly associated with high mortality among untreated cases of HCC. The median survival period of patients with $\mathrm{HCC}$ using the Child-Pugh class has also been observed to reduce progressively according to worsening liver disease severity (Cabibo et al. 2012). Other indices that contribute to a short survival time are a positive HBsAg status, high levels of alpha-fetoprotein, alanine aminotransferase (ALT) and aspartate aminotransferase (AST). (Abbas et al. 2008, Changchien et al. 2008 and Zhang et al. 2014).

Most cases of HCC in Nigeria usually present at a late stage of the disease when virtually nothing can be done other than giving supportive care. 
Hepatitis B virus (HBV) infection is also the commonest cause of HCC in Nigeria, with some contributions from hepatitis $\mathrm{C}(\mathrm{HCV})$ infection and alcohol consumption (Okonkwo et al. 2011). There are almost no reports to date among untreated cases of HCC in Nigeria that have studied the influence of laboratory and clinical parameters on the survival of HCC on supportive care. It is therefore important to identify clinical and pathological characteristics in relation to outcomes of cases on supportive care in Nigeria.

\section{Methods}

This was a hospital-based study of cases of HCC on supportive care that presented at a late stage to the Obafemi Awolowo University Teaching Hospital in Nigeria. They were prospectively and consecutively recruited into an HCC cancer data registry (HCDR) of the Gastro-intestinal unit of the hospital after an informed consent from January 2010 to June 2016. A total of 174 cases were seen within the study period. Twenty five (25) cases were excluded from the analysis. Two (2) of those excluded were at the advanced stage and were treated with Sorafenib, while 23 cases were excluded due to incomplete data.

Hepatocellular carcinoma was diagnosed based on history and clinical examination findings suggestive of the disease as well as radio-diagnostic features, cytology/histology and or tumour marker. Detailed findings on clinical examination, including the presence or absence of ascites, as well as laboratory tests, which included haematology, chemistry, coagulation tests and serological tests for hepatitis $\mathrm{B}$ and $\mathrm{C}$ viruses, were carried out at presentation when the cases were seen and the diagnosis of $\mathrm{HCC}$ was made. Other lifestyle habits, such as herbal use and alcohol consumption, were quantified and a value up to 50 grams per day for up to 10 years was considered a significant value for those that drank alcohol (Ndububa et al. 2010).

The cases were followed up at diagnosis in the clinic, while on admission and after discharge from the hospital. Outcome was taken as the time of death during clinic attendance, on admission or after discharge from the hospital. Total number of days spent was taken as the time from first contact in the hospital when the diagnosis of HCC was made to the time patient died. The date of death was obtained through phone contact to the relatives for cases that were managed on outpatient basis or discharged cases from the hospital. Where phone contact was not possible, the date of death was taken as the day after the last clinic visit. Details of bio-data as well as physical and systemic examination findings in the abdomen and laboratory tests were recorded in a proforma. The study was reviewed and approved by the Institutional Review Board of our hospital (Number: IRB/IEC/0004553 and NHREC/27/02/2009). 


\section{Statistical analysis}

The data collected were entered into and analyzed using SPSS version 20. Simple descriptive and inferential statistics were performed and the results presented. Survival outcome was calculated and presented as in the first fourteen (14) days, between first fifteen days and one month, and after one month to two years respectively. Clinical and laboratory parameters of the cases were computed as mean values and presented according to the survival periods. Comparison of the clinical and laboratory indices was made for the various periods of death. Cases were divided into two age groups, those aged 40 years and below and those aged 41 years and above, to differentiate them into young and old cases of HCC according to previous studies from Asia and Europe respectively (Chang et al. 2008 and Niederie et al. 2012). Clinical and laboratory indices were also compared for the two age groups. Kaplan-Meier survival analysis was done to determine the mean and median survival time after diagnosis for cases by age and sex. A p value of $<0.05$ was accepted as significant.

\section{Results}

A total of 149 cases were analyzed. Their ages ranged from 18-87 years with a mean age (SD) of 45.0 (14.3) years. There were $120(80.5 \%)$ males and $29(19.5 \%)$ females with an M: F ratio of 4:1. Sixty two artisans, $(41.6 \%)$ and 37 traders $(24.8 \%)$ constituted the majority of the cases. Sixty-nine (46.3\%) were young while $80(53.7 \%)$ were old cases of HCC. Aetiological factors identified were hepatitis B infection in $99(66.4 \%)$ while the number that took alcohol in significant quantity was $20(13.4 \%)$, $\mathrm{HCV}$ was $3(2 \%)$ while the number that took local herbal remedies was 34 (22.8\%). Overlap of risk factors also occurred in various combinations (Table1).

Table 1.Basic Demographic Characteristics and risk factors of Cases

\begin{tabular}{lll} 
Variables & & No $(\%)$ \\
\hline Sex & Male & $120(80.5)$ \\
& Female & $29(19.5)$ \\
Occupation & Unemployed & $21(14.1)$ \\
& Traders & $37(24.8)$ \\
& Civil servants & $29(19.5)$ \\
& Artisans & $62(41.6)$ \\
Ethnicity & Yoruba & $136(91.3)$ \\
& Igbo & $7(4.7)$ \\
Marital status & *Others & $6(4.0)$ \\
& Single & $24(16.1)$ \\
& Married & $119(79.9)$ \\
& Divorced & $2(1.3)$ \\
\hline
\end{tabular}




\begin{tabular}{llc}
\hline \multirow{4}{*}{ HBsAg } & Widow & $4(2.7)$ \\
HCV & Negative & $50(33.6)$ \\
& Positive & $99(66.4)$ \\
Alcohol & Negative & $146(98.0)$ \\
& Positive & $3(2.0)$ \\
& Non drinkers & $91(61.1)$ \\
Mortality pattern & Significant alcohol drinkers & $20(13.4)$ \\
& Non- significant alcohol drinkers & $38(25.5)$ \\
& First 14 days & $61(40.9)$ \\
& 15days to 30 days & $38(25.5)$ \\
& 31 days to 730 days & $50(33.6)$ \\
& HBV+ HCV+ Alcohol & $33(22.2)$ \\
& Herbal medications & $34(22.8)$ \\
& Herbal + HBV+ HCV+ Alcohol & $73(48.9)$ \\
& No risk factor identified & $9(6.04)$ \\
\hline
\end{tabular}

Keys: $\mathrm{HCV}=$ Hepatitis C Virus, HIV = Human Immunodeficiency Virus *Other tribes: Ebira=1, Igala=1, Idoma=1, Edo=1 \& Urhobo $=2$.** Multiple response

The mortality pattern showed that out of the 149 cases, $52(34.9 \%)$ died while on hospital admission, 55 (36.9\%) were admitted and died after discharge, while $42(28.2 \%)$ were managed on an outpatient basis and died at home.

The time of death showed that 61(40.9\%) died within the first 14 days, while $38(25.5 \%)$ and $50(33.6 \%)$ died between fifteen days and one month, and after one month and two years respectively (Table 1). The overall median survival for all cases was 20 days, while general survival was $59.1 \%$ at two weeks, $33.5 \%$ at one month and only $7.3 \%$ surviving beyond thirty- one days to two years respectively. The median survival, according to the CTP classes, were: CTP class A: 36 days (ranged 4 to 730 days), CTP class B: 22 days (ranged 1 to 210 days) and CTP class C: 14 days (ranged 2 to 660 days).

The clinical history and physical examination of cases showed that a higher proportion of cases that died early had statistically significant clinical features of a decompensated HCC (abdominal pain, $p=0.02$; yellow sclera, $p$ $=0.001$ and jaundice on examination, $p=0.01$ ) than cases that died afterwards (Table 2). 
Table 2. Clinical presentation and examination findings and their relationship to patients' time of death.

\begin{tabular}{|c|c|c|c|c|c|}
\hline \multicolumn{2}{|c|}{$\begin{array}{l}\text { Patients' complaints } \\
\text { and examinations findings }\end{array}$} & $\begin{array}{c}\text { Early death } \\
\text { (first 14days) } \\
\text { No }\end{array}$ & $\begin{array}{c}\text { Late early } \\
\text { death (15-30)days) } \\
\text { No }\end{array}$ & $\begin{array}{c}\text { Late } \\
>30 \text { days death } \\
\text { No }\end{array}$ & p-value \\
\hline \multirow[t]{2}{*}{ Upper abdominal pain } & Yes & 50 & 38 & 40 & 0.02 \\
\hline & No & 11 & 0 & 10 & \\
\hline \multirow{2}{*}{ Weight loss } & Yes & 53 & 32 & 40 & 0.62 \\
\hline & No & 8 & 6 & 10 & \\
\hline \multirow[t]{2}{*}{ Yellow sclera } & Yes & 48 & 22 & 26 & 0.009 \\
\hline & No & 13 & 16 & 24 & \\
\hline \multirow[t]{2}{*}{ Abdominal swelling } & Yes & 50 & 33 & 41 & 0.79 \\
\hline & No & 11 & 5 & 9 & \\
\hline \multirow[t]{2}{*}{ Jaundice on examination } & Yes & 51 & 27 & 29 & 0.01 \\
\hline & No & 10 & 11 & 21 & \\
\hline \multirow[t]{2}{*}{ Ascites } & None & 12 & 11 & 19 & 0.102 \\
\hline & Present & 49 & 27 & 31 & \\
\hline \multirow[t]{2}{*}{ PV Thrombosis } & Yes & 1 & 3 & 4 & 0.194 \\
\hline & No & 60 & 35 & 46 & \\
\hline \multirow[t]{3}{*}{ CTP Class } & A & 3 & 5 & 14 & 0.002 \\
\hline & B & 20 & 17 & 20 & \\
\hline & $\mathrm{C}$ & 38 & 16 & 16 & \\
\hline
\end{tabular}

KEYS: $\mathrm{PV}=$ Portal vein, $\mathrm{CTP}=$ Child-Pugh class

The cases of HCC that died within the first 14 days had statistically significant elevated levels of serum creatinine, $p=0.05$, total and conjugated bilirubin, $\mathrm{p}=0.001$; elevated AST; $\mathrm{p}=0.02$; ALT, $\mathrm{p}=0.001$ and hyponatremia, $\mathrm{p}=0.001$ compared with those that died later (Table 3 ).

Table 3Laboratory value and their relationship to patients' time of death

\begin{tabular}{lllll}
\hline $\begin{array}{l}\text { Laboratory } \\
\text { variables }\end{array}$ & $\begin{array}{l}\text { Early death (first 14days) } \\
\text { Mean }(+\mathrm{SD})\end{array}$ & $\begin{array}{l}\text { Late early death(15-30) } \\
\text { days Mean }(+\mathrm{SD})\end{array}$ & $\begin{array}{c}\text { Late }>30 \text { days death } \\
\text { Mean }(+\mathrm{SD})\end{array}$ & p-value \\
\hline $\mathrm{WBC}(\mathrm{cmm})$ & $8756.4 \pm 5542.3$ & $7927 \pm 4528.6$ & $8281.0 \pm 4051.8$ & 0.71 \\
$\mathrm{~K}^{+}(\mathrm{mmol} / \mathrm{l})$ & $6.6 \pm 18.6$ & $3.6 \pm 0.5$ & $4.6 \pm 4.3$ & 0.50 \\
$\mathrm{Na}^{+}(\mathrm{mmol} / \mathrm{l})$ & $128.1 \pm 6.5$ & $129.1 \pm 5.5$ & $131.9 \pm 5.8$ & 0.001 \\
Urea $(\mathrm{mmol} / \mathrm{l})$ & $8.4 \pm 6.6$ & $6.3 \pm 2.8$ & $7.4 \pm 7.0$ & 0.27 \\
$\mathrm{Creatinine} \mathrm{(umol/l)}$ & $126.1 \pm 75.6$ & $99.9 \pm 32.4$ & $102.1 \pm 42.6$ & 0.053 \\
$\mathrm{~B} 1(\mathrm{umol} / \mathrm{l})$ & $181.9 \pm 165.3$ & $92.1 \pm 106.0$ & $60.6 \pm 69.8$ & 0.000 \\
$\mathrm{~B} 2(\mathrm{umol} / \mathrm{l})$ & $137.9 \pm 146.6$ & $68.6 \pm 91.1$ & $45.9 \pm 62.4$ & 0.000 \\
$\mathrm{AST}(\mathrm{iu} / \mathrm{l})$ & $105.1 \pm 61.8$ & $80.7 \pm 50.1$ & $65.5 \pm 43.8$ & 0.001 \\
$\mathrm{ALT}(\mathrm{iu} / \mathrm{l})$ & $41.8 \pm 35.0$ & $28.4 \pm 21.3$ & $33.9 \pm 28.4$ & 0.02 \\
ALK (iu/l) & $446.0 \pm 320.0$ & $352.4 \pm 237.7$ & $352.0 \pm 282.0$ & 0.24 \\
Albumin $(\mathrm{g} / \mathrm{l})$ & $30.1+6.1$ & $31.5 \pm 6.0$ & $32.7 \pm 6.4$ & 0.107 \\
INR & $1.5 \pm 0.6$ & $1.4 \pm 0.4$ & $1.4 \pm 0.4$ & 0.36 \\
\hline
\end{tabular}

KEYS: WBC $=$ White blood cells, $\mathrm{K}^{+}=$potassium, $\mathrm{Na}^{+}=$Sodium, $\mathrm{B}_{1}=$ Total bilirubin, $\mathrm{B}_{2}$

$=$ Conjugated bilirubin, AST=Aspartate aminotransferase, ALT=Alanine aminotransferase,

$\mathrm{INR}=$ International normalized ratio, ALK= Alkaline phosphatase. 
When the cases were divided into old and young $\mathrm{HCC}$, a higher proportion of young cases with $\mathrm{HCC}$ had a statistically significant positive test for HBsAg than old cases of HCC, $\mathrm{p}=0.005$ [HCC cases: 40 years and below, HBsAg positive 54 (54.5\%), HBsAg negative 15 (30\%), HCC cases 41 years and above, HBsAg positive 45 (45.5\%), HBsAg negative 35 (70\%)].

Kaplan-Meier survival analysis showed that the mean and median survival time by age was 111.2 days vs. 162.4 days, 35 days vs. 34 days for young and old cases respectively; while by sex, it was 99 days vs. 124.8 days, 34 days vs. 35 days for males and females respectively (Table 4). KaplanMeier survival analyses showed that $50 \%$ were dead by 35 days of care among young cases (Figure 1), while 50\% were dead by 34 days of care in males (Figure 2).

Table 4.The comparison of mean and median survival time of HCC patients by age and sex

\begin{tabular}{|c|c|c|c|c|c|c|c|c|}
\hline Variable & \multicolumn{3}{|c|}{ Mean } & \multicolumn{4}{c|}{ Median } \\
\hline Age group (years) & Estimate & S.E. & \multicolumn{2}{|c|}{$95 \%$ CI } & Estimate & S.E. & \multicolumn{2}{c|}{$95 \%$ CI } \\
\hline$\leq 40$ & 111.2 & 34.3 & 44.0 & 178.4 & 35.0 & 7.2 & 21.0 & 49.0 \\
\hline$>40$ & 162.4 & 43.4 & 77.4 & 247.4 & 34.0 & 8.2 & 18.0 & 50.0 \\
\hline Sex & \multicolumn{4}{|c|}{ Mean } & \multicolumn{5}{c|}{ Median } \\
\hline Male & 99.0 & 17.5 & 64.7 & 133.3 & 34.0 & 7.0 & 20.4 & 47.6 \\
\hline Female & 124.8 & 53.2 & 20.6 & 229.0 & 35.0 & 8.7 & 17.9 & 52.1 \\
\hline
\end{tabular}

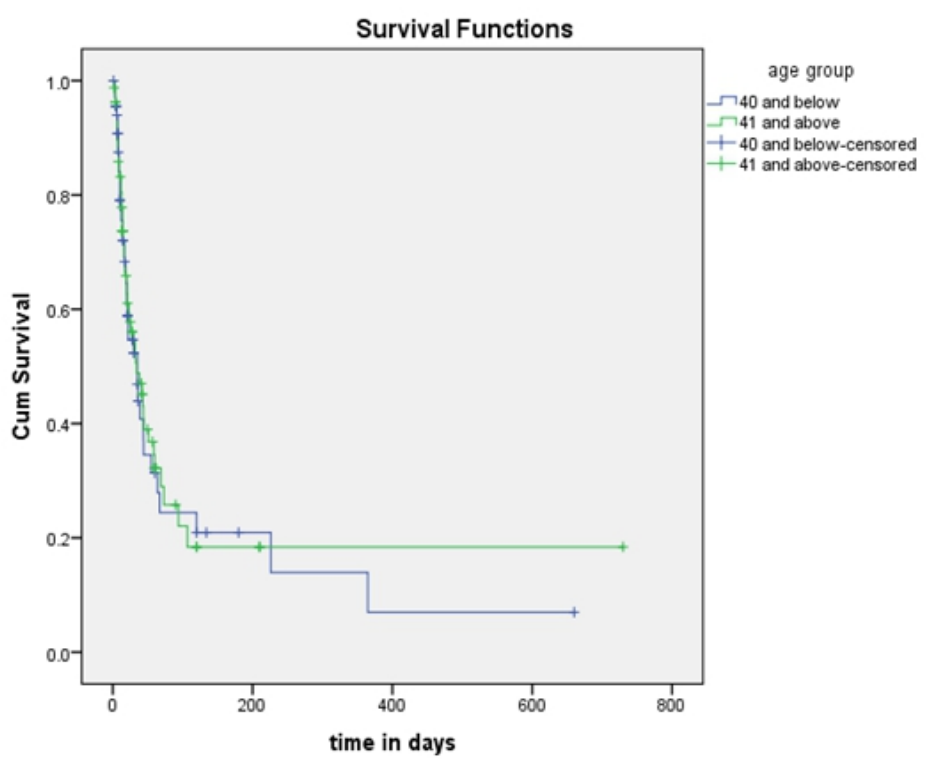

Figure 1: Survival analysis of young and old HCC cases 


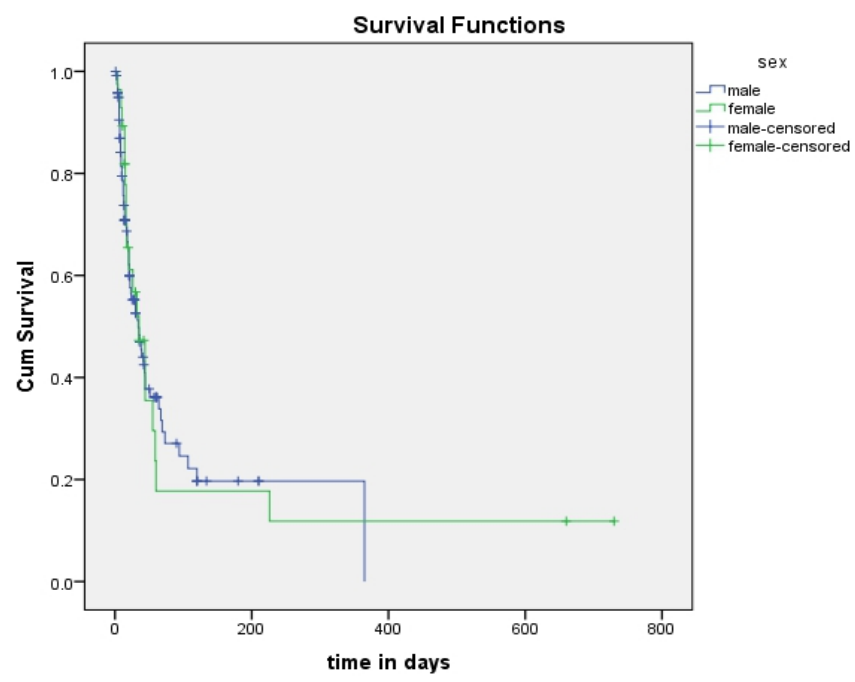

Figure 2: Survival analysis of HCC cases by sex

The mean and median survival time for cases of HCC with neutrophil cell count suggestive of infection was significantly shorter than those without infection 31.0 and 17.5 days vs. 59.7 and 23 days respectively, $\mathrm{p}=0.05$ (Table 5). Significant factors associated with survival outcome were older age, female sex, abdominal pain, jaundice, elevated creatinine, bilirubin, AST, ALT, neutrophil cell count and hyponatreamia.

Table 5. Clinical and laboratory qualities of HCC cases

\begin{tabular}{|c|c|c|c|c|c|}
\hline \multicolumn{2}{|c|}{ Parameters } & Number & Mean duration alive & Median & p-value \\
\hline \multirow{2}{*}{ Bilirubin, umol/l } & $<171$ & 106 & 48.26 & 21.5 & \\
\hline & $>171$ & 43 & 33.16 & 12.0 & 0.356 \\
\hline \multirow[t]{2}{*}{ Neutrophil } & $<70 \%$ & 67 & 59.69 & 23.0 & \\
\hline & $>70 \%$ & 82 & 31.01 & 17.5 & 0.053 \\
\hline \multirow[t]{2}{*}{ Liver Failure } & Yes & 31 & 21.68 & 14.0 & \\
\hline & No & 118 & 49.75 & 21.0 & 0.123 \\
\hline \multirow[t]{2}{*}{ HBsAg } & Positive & 99 & 35.83 & 19.0 & \\
\hline & Negative & 47 & 62.09 & 21.0 & 0.103 \\
\hline \multirow[t]{2}{*}{ INR } & $\leq 1.3$ & 74 & 46.41 & 21.0 & \\
\hline & $\geq 1.4$ & 75 & 41.44 & 18.0 & 0.738 \\
\hline \multirow[t]{2}{*}{ Albumin $\mathrm{g} / \mathbf{l}$} & $\leq 35$ & 108 & 46.90 & 19.5 & \\
\hline & $\geq 36$ & 41 & 36.02 & 25.0 & 0.512 \\
\hline
\end{tabular}

KEYS: CTP=Child-Pugh class, INR= International normalized ratio

\section{Discussion}

This study assessed the factors associated with the survival outcome of patients with HCC in a cohort of Nigerian patients on supportive care. 
The survival pattern showed that $59.1 \%$ were alive at two weeks, 33.6 $\%$ at one month, and only $7.3 \%$ surviving beyond thirty one days to two years. This is in sharp contrast to cases of HCC from Europe, where those that presented late without treatment survived for a median period of 7 to 9 months (Cabbibo et al. 2012 and Giannini et al. 2015). This observed difference may be due to the state of the cases at presentation, as many presented late with infection and hepato-renal failure. Studies from developed countries have reported that survival of HCC is affected by low serum sodium, high levels of alkaline phosphatase, AST, ALT, bilirubin, INR, and low albumin, as well as the presence of ascites (Abbas et al. 2008, Changchien 2008 and Zhang et al. 2014,). This paper shows similar findings to reports from other studies, even though INR and patients with ascites did not contribute significantly to death among those that died early. The cases that died early from the findings in this cohort had, in addition, elevated creatinine. The reason for this could probably have been due to hepato-renal failure. Also, the serum sodium showed that hyponatreamia contributed significantly to death, more especially among cases that died early. Studies from other countries have reported similar findings with excess mortality in patients with CLD having hyponatreamia (Jen et al. 2010 and Moini et al. 2011).

This study reported that survival was better for old and female cases of HCC than for young and male cases. The implication of these findings may require further research. However, some studies from Asia and Europe reported contrary findings that survival was similar for both old and young cases of HCC, while some studies even reported better survival for young people (Abbas et al. 2008 and Zhang et al. 2014).

The symptoms of upper abdominal pain and yellowness of the sclera and clinical examination finding of jaundice were significantly associated with early death. The explanation for these might be that these patients probably had ruptured liver nodule and probably had bleeding into the liver or peritoneum; both conditions could lead to early death. Also, the complication of portal vein thrombosis was common among those that survived for long. This finding is at variance with the report by Chang et al. (2008) that long term survivors of HCC had less incidence of portal vein thrombosis. The number of cases with this condition was small and not statistically significant; therefore, we cannot make a strong statement out of it.

The median survival using the CTP class showed that the survival of cases in this study is shorter than that reported by Cabibo et al. (2012) among untreated cases where those in CTP class C survived for a median period of 3.7 months.

The mean age of patients with $\mathrm{HCC}$ in this study differs from cases of HCC from other studies outside Nigeria (Ahmadzadehfar et al. 2014, Park et al. 2015 and Debes et al. 2018). HCC occurred at a lower mean age in Nigeria 
which is different from HCC from America mostly caused by HCV (Park et al. 2018), but close to those in Asia which is due to HBV. The lower mean age in Nigeria is probably due to the age at infection of $\mathrm{HBV}$, and low $\mathrm{HBV}$ vaccine coverage (Sadoh et al. 2014). Also, more males than females had HCC probably because males are more exposed to $\mathrm{HBV}$ and alcohol consumption, and cytokines may also play a role (Gomes et al. 2013).

The age group of 41 years and above had more cases of HCC and this agrees with reports from within and outside Nigeria (Neef et al. 2009, Okonkwo et al. 2011, Yang et al. 2017, and Debes et al. 2018). The high incidence in this age group might be the age at infection of $\mathrm{HBV}$ and the length of time it takes for cancer to develop in a person infected with HBV.

HBsAg positive test was seen more among young cases and this agrees with reports from Asia that HCC among young people is commonly due to HBV infection (Debes et al. 2018). The result of HCV showed that the virus does not play any significant role in the aetiology of HCC from the findings in this study. This study found that $13.4 \%$ cases of HCC had significant alcohol consumption. This shows that alcohol is a strong etiological factor. This study also reported that $22.8 \%$ took local herbal preparations; some herbal preparations contain multiple hepatotoxins and cause direct liver injury (Firenzuoli et al. 2013, Amadi et al. 2018). This is an area for further studies. In conclusion, factors associated with survival outcome of cases of HCC included elevated values of AST, ALT, total and conjugated bilirubin, alkaline phosphatase, creatinine and hyponatremia. Clinical findings revealed that those with jaundice and abdominal pain also had short survival period. Survival is also affected by sex and age of patients. Higher proportion of young cases of $\mathrm{HCC}$ were $\mathrm{HBsAg}$ positive. $\mathrm{HBV}$ and alcohol remain strong etiological factors. The number surviving beyond the first one month after diagnosis calls for serious concern. Therefore, preventive strategies targeting HBV and alcohol use reduction and early diagnosis of HCC toward aggressive curative treatment are advocated.

\section{Limitations and strength of this study}

This study is among the first few prospective cohort studies on HCC in Nigeria. It is also among the first few survival studies that examined factors affecting survival of HCC patients on supportive care. Those that were lost to follow up were censored in the Kaplan Meier survival analysis. In addition, history obtained from patients and phone calls to their relations assumed that they had given a true account of the cases.

\section{Funding}

This study was not funded. 


\section{Competing interest}

We, the authors, declare no competing interest regarding the publication of this article.

\section{References:}

1. Abbas Z., Siddiqui A.U., Luck N.H., Hassan M., Mirza R., Naqvi A., Rizvi A.H. (2008). Prognostic factors of survival in patients with nonresectable hepatocellular carcinoma: hepatitis $\mathrm{C}$ versus miscellaneous etiology. J Pak Med Assoc. 58(11): 602-7.

2. Ahmadzadehfar H., Habibi E., Ezziddin S., Wilhelm K., Fimmers R., Spengler U., Palmedo H., Strunk H., Schild H.H., Biersack H.J., Risse J. (2014). Survival after 1311-labeled lipiodol therapy for hepatocellular carcinoma. A single-center study based on a long term follow-up. Nuklearmedizin. 53(2):46-53.

3. Amadi C.N., Orisakwe O.E. (2018). Herb induced liver injuries in developing nations: an update. J Toxics 24(6): 1-13.

4. Cabibbo G., Maida M., Genco C., Parisi P., Peralta M., Antonucci M., Brancatelli G., Camma C., Crai A., Di Marco V. (2012). Natural history of unresectable hepatocellular carcinoma: A retrospective cohort study. World J Hepatol. 4(9): 256-61.

5. Changchien C.S., Chen C.L., Yen Y.H., Wang J. H., Hu T.H., Lee C.M., Wang C.C., Cheng Y.F., Huang Y.J., Lin C.Y., Lu S.N. (2008). Analysis of 6381 hepatocellular carcinoma patients in southern Taiwan: prognostic features, treatment outcome, and survival. J Gastroenterol. 43(2): 159-70.

6. Chang P. E., Ong W.C., Liu H.F., Tan C.K. (2008). Is the prognosis of young patients with hepatocellular carcinoma poorer than the prognosis of older patients? A comparative analysis of clinical characteristics, prognostic features, and survival outcome. J Gastroenterol. 43(11): 881-8.

7. Debes J.D., Chan A.J., Balderramo D., Kikuchi L., Gonzalez Ballerga E., Prieto J.E., Tapias M., Idrovo V., Davalos M.B., Cairo F., Barreyro F.J., Paredes S., Hernandez N., Avendaño K., Diaz Ferrer J., Yang J.D., Carrera E., Garcia J.A., Mattos A.Z., Hirsch B.S., Gonçalves P.T., Carrilho F.J., Roberts L.R. (2018). Hepatocellular carcinoma in South America: Evaluation of risk factors, demographics and therapy. Liver Int. 38(1):136-143.

8. Firenzuoli F., Gori L., Mugelli A., Vannacci A. (2013) Current issues and perspectives in herbal hepatotoxicity: a hidden epidemic. Intern Emerg Med 8:3-5. 
9. Gomes M.A., Priolli D.G., Tralhao J.G., Botelho M.F. (2013). Hepatocellular carcinoma: epidemiology, biology, diagnosis, and therapies. Rev Assoc Med Bras. 59(5):514-24.

10. Giannini E.G., Farinati F., Ciccarese F., Pecorelli A., Rapaccini G.L., Di Marco M., Benvegnu L., Caturelli E., Zoli M., Borzio F., Chiaramonte M., Trevisani F. (2015). Prognosis of untreated hepatocellular carcinoma. Hepatology. 61(1): 184-90.

11. Jenq C.C., Tsai M.H., Tian Y.C., Chang M.Y., Lin C.Y., Lien J.M., Chen Y.C., Fang J.T., Chen P.C., Yang C.W. (2010). Serum sodium predicts prognosis in critically ill cirrhotic patients. J Clin Gastroenterol. 44(3): 220-6.

12. Moini M.1., Hoseini-Asl M.K., Taghavi S.A., Sagheb M.M., Nikeghbalian S., Salahi H., Bahador A., Motazedian M., Jafari P., Malek-Hosseini S.A. (2011). Hyponatremia a valuable predictor of early mortality in patients with cirrhosis listed for liver transplantation. Clin Transplant. 25(4): 638-45.

13. Ndububa, D.A., Ojo O.S., Adetiloye, V.A., Aladegbaiye, A.O., Adebayo, R.A., Adekanle O. (2010). The contribution of alcohol to chronic liver disease in patients from South-West Nigeria. Niger J Clin Pract. 13(4): 360-4.

14. Neeff H., Makowiec F., Harder J., Gumpp V., Klock A., Thimme R., Drognitz O., Hopt U.T. (2009). Hepatic resection for hepatocellular carcinoma-results and analysis of the current literature. Zentralbl Chir. 134(2): 127-35.

15. Niederle I.M., Wörns M.A., Koch S., Nguyen-Tat M., Düber C., Otto G., Schuchmann M., Galle P.R., Weinmann A. (2012). Clinicopathologic features and prognosis of young patients with hepatocellular carcinoma in a large German cohort. J Clin Gastroenterol. 46 (9): 775-8.

16. Okonkwo U.C., Nwosu M.N., Ukah C., Okpala O.C., Ahaneku J.I. (2011). The clinical and pathological features of hepatocellular carcinoma in Nnewi, Nigeria. Niger J Med. 20(3): 366-71.

17. Park J.W., Chen M., Colombo M., Roberts L.R., Schwartz M., Chen P.J., Kudo M., Johnson P., Wagner S., Orsini L.S., Sherman M. (2015). Global patterns of hepatocellular carcinoma management from diagnosis to death: the BRIDGE Study. Liver Int. 35(9): 2155-66.

18. Sadoh AE, Sadoh WE. Does Nigeria need the birth dose of hepatitis B vaccine? Niger J Paed 2014; 41: 104-109.

19. Tinoco-Gonzalez J., Suarez-Artacho G., Bernal-Bellido C., CepedaFranco C., Ramallo-Solis I., Marin-Gomez L., Alamo-Martinez JM., Serrano-Diez-Canedo J., Padillo-Ruiz J., Gomez-Bravo M.A. (2016). 
Analysis of the first 1000 liver transplants in Virgen del Rocio hospital. Transplant Proc. 48(9): 2973-2976.

20. Yang J.D., Mohamed E.A., Aziz A.O., Shousha H.I., Hashem M.B., Nabeel M.M., Abdelmaksoud A.H., Elbaz T.M., Afihene M.Y., Duduyemi B.M., Ayawin J.P., Gyedu A., Lohouès-Kouacou M.J., Ndam A.W., Moustafa E.F., Hassany S.M., Moussa A.M., Ugiagbe R.A., Omuemu C.E., Anthony R., Palmer D., Nyanga A.F., Malu A.O., Obekpa S., Abdo A.E., Siddig A.I., Mudawi H.M., Okonkwo U., Kooffreh-Ada M., Awuku Y.A., Nartey Y.A., Abbew E.T., Awuku N.A., Otegbayo J.A., Akande K.O., Desalegn H.M., Omonisi A.E., Ajayi A.O., Okeke E.N., Duguru M.J., Davwar P.M., Okorie M.C., Mustapha S., Debes J.D., Ocama P., Lesi O.A., Odeghe E., Bello R., Onyekwere C., Ekere F., Igetei R., Mah'moud M.A., Addissie B., Ali H.M., Gores G.J., Topazian M.D., Roberts L.R. (2017). Characteristics, management, and outcomes of patients with hepatocellular carcinoma in Africa: a multicountry observational study from the Africa liver cancer consortium. Lancet Gastroenterol Hepatol; 2(2): 103-111.

21. Zhang J.F., Shu Z.J., Xie C.Y., Li Q., Jin X.H., Gu W., Jiang F. J., Ling C. Q. (2014). Prognosis of unresectable hepatocellular carcinoma: comparison of seven staging systems (TNM, Okuda, BCLC, CLIP, CUPI, JIS, CIS) in a Chinese cohort. PloS One. 9(3): e88182. 